\title{
La vinculación de los poderes del Estado a la concretización de derechos fundamentales sociales: ¿hay espacio para un margen de apreciación del legislador? ${ }^{1}$
}

\author{
The Linkage of State's Powers to the concretization of Fundamental Social \\ Rights: Is there space for a legislative margin of appreciation?
}

Rosana Helena MAAS ${ }^{2}$

Maria Valentina DE MORAEs ${ }^{3}$

Resumen: La efectuación y la protección de los derechos fundamentales sociales son finalidades del Estado, vinculando a todos los Poderes Estatales en esta tarea. Delante de eso y de las problemáticas y debates que rodean los derechos fundamentales sociales, especialmente aquí investigado su carácter multifuncional y las posibilidades de tutela jurisdiccional, se objetiva analizar la viabilidad del reconocimiento de un margen de apreciación del legislador ante a esos derechos. Se cuestiona, así, si frente a esas características y de la vinculación estatal a su

\footnotetext{
${ }^{1}$ Este artículo fue realizado con el apoyo de Coordenação de Aperfeiçoamento de Pessoal de Nível Superior -Brasil (CAPES)- Código de Financiamento 001, es resultado de las atividades del proyecto de investigación “"Fórmulas" de exploración del "margen de apreciación del legislador" (Beurteiligungsspielraum des Gesetzgebers) en la confección de políticas públicas de inclusión social e de protección de minorías por el Supremo Tribunal Federal y por la Corte Interamericana de Derechos Humanos", financiado pelo CNPq (Edital Universal - Edital 14/2014 - Processo 454740/2014-0) y por la FAPERGS (Programa Pesquisador Gaúcho - Edital 02/2014 - Processo 2351-2551/14-5). Investigación vinculado al Grupo de Investigación "Jurisdição Constitucional aberta" (CNPq) y desarrollado junto al Centro Integrado de Estudios e Invstigaciones em Políticas Públicas - CIEPPP (financiado pelo FINEP) y el Observatório da Jurisdição Constitucional Latino-Americana (financiado pelo FINEP), ligados al Programa de Post Graduación en Dercho- Magíster y Doctorado de la Universidade de Santa Cruz do Sul - UNISC.

${ }^{2}$ Pós-doutorado pela Paris Lodron Universität Salzburg (2018) e doutorado em Direito pela Universidade de Santa Cruz do Sul UNISC (2016), com doutorado sanduíche na Ernst-Moritz-Arndt-Universität Greifswald, Rechts- und Staatswissenschaftliche Fakultät (2016). Professora concursada da Universidade de Santa Cruz do Sul - UNISC, no Curso de Direito e na Pós-Graduação em Direito, onde ministra matérias relacionadas ao Direito Civil, ao Direito Constitucional e a Teoria do Direito. É integrante do grupo de estudos "Jurisdição Constitucional aberta" coordenado pela Profa. Pós-Doutora Mônia Clarissa Hennig Leal, vinculado e financiado pelo CNPq. É autora de livros e artigos publicados no Brasil e no exterior. Currículo Lattes: http://lattes.cnpq.br/2204113976797800. Orcid: https://orcid.org/0000-0002-9930-309X. Correo electrónico: rosanamaas@unisc.br

${ }^{3}$ Doutoranda no Programa de Pós-Graduação Stricto Sensu em Direitos Sociais e Políticas Públicas da Universidade de Santa Cruz do Sul - UNISC, na linha Dimensões Instrumentais das Políticas Públicas. Bolsista PROSUC/CAPES. Mestre em Direito pela Universidade de Santa Cruz do Sul - UNISC, com bolsa PROSUC/CAPES e bolsa CAPES no Processo № 88887.156773/2017-00, Edital PGCI № 02/2015, Universidade de Santa Cruz do Sul (Brasil) e Universidad de Talca - Centro de Estudios Constitucionales de Chile - CECOCH (Chile). Membro do Grupo de Pesquisa "Jurisdição Constitucional aberta: uma proposta de discussão da legitimidade e dos limites da jurisdição constitucional - instrumentos teóricos e práticos", vinculado ao CNPq e coordenado pela professora Pós-Drª Mônia Clarissa Hennig Leal. Lattes: http://lattes.cnpq.br/2400734786644430. Orcid: https://orcid.org/00000002-8298-5645. Correo electrónico: moraesmvalentina@gmail.com
} 
protección, hay espacio para un margen de apreciación legislativa en la implementación de los derechos fundamentales sociales, utilizándose, para tanto, el método deductivo y la técnica de investigación bibliográfica. Es posible concluir, frente al estudio realizado, que el espacio de decisión legislativa no es ilimitado, estando el legislador, como los demás Poderes Estatales, vinculado a la implementación de los derechos fundamentales sociales, siendo él el primero a garantizarlos, legitimándose la actuación judicial ante su omisión.

Palabras clave: Control de constitucionalidad; derechos fundamentales sociales; margen de apreciación del legislador; principio de la separación de poderes

\begin{abstract}
The effectiveness and protection of the fundamental social rights are purposes of the State, linking all the State Powers in this task. In face of such a situation, and of the problems and debates that surround the fundamental social rights, notably peered here their multifunctional nature and the possibilities of judicial protection, it is aimed to analyze the feasibility of the recognition of a margin of appreciation from the legislator in relation to these rights. It is asked, thus, if, in front of these features and of the state link to their protection, there is space for a legislative margin of appreciation in the implementation of the fundamental social rights, using, for this purpose, the deductive method and the bibliographic research technic. It is possible to conclude, from the conducted study, that the space for legislative decision is not unlimited, being the legislator, like the other State Powers, linked to the implementation of the fundamental social rights, being him the first to guarantee them, legitimating himself to the judicial action in face of his omission.
\end{abstract}

Keywords: Constitutionality Control; Fundamental Social Ritghs; Margin of Appreciation from the Legislator; Separation of Powers Principle

\title{
1. Introducción
}

El reconocimiento de los derechos fundamentales por los Estados sigue siendo fortalecido con los diferentes mecanismos de protección y efectuación a ellos, restringiendo la posibilidad de una mera elección política para su efectuación. A lo que se refiere a los derechos fundamentales de carácter social, algunas características aún dificultan su máxima concretización, como los costos generados al Estado, no excluyendo otra gama de problemáticas involucrando esta naturaleza de derechos, como la propia disponibilidad del objeto.

La Constitución Federal brasileña, diferente de las anteriores, además de reconocer el carácter fundamental a los derechos sociales, también les atribuye aplicabilidad inmediata, reforzando, aún, la vinculación de los tres Poderes del Estado a su concretización. Por esa razón, sumándose a su carácter multifuncional, bien como la doble posibilidad de tutela jurisdiccional —objetiva y subjetiva—, se debe cuestionar si, delante de esas características y de la vinculación 
estatal a su protección, hay espacio para un margen de apreciación legislativa en la implementación de los derechos fundamentales sociales, utilizándose, para tanto, el método deductivo y la técnica de investigación bibliográfica.

Se discute, así, el carácter multifuncional de los derechos fundamentales y, pues, las formas de tutela de esos derechos - objetiva y subjetiva - siendo presentados, por fin, aspectos de la relación entre Poderes del Estado y del margen de apreciación legislativa -como reconocimiento del espacio decisorio del legislador por parte del Poder Judiciario-, para comprender si hay y cuál es el espacio de decisión legislativa en el que toca a la efectuación de derechos fundamentales sociales, respondiendo la problemática propuesta en el trabajo. Se inicia, por lo tanto, analizando las características y la naturaleza de los derechos fundamentales sociales.

\section{Los derechos fundamentales sociales y su carácter multifuncional}

A los derechos fundamentales se atribuye una función de defensa (negativa) que, a la vez, remonta a los derechos más básicos del ciudadano, los derechos de libertad, siendo considerada su función originaria ${ }^{4}$. Los derechos de defensa o de abstención, oriundos y conectados con el individuo, son, en su visión clásica, resultantes de un Estado liberal-burgués, y poseen un carácter negativo, o sea, comprenden derechos contra/frente al Estado, con la idea de que el Estado no debe intervenir en la libertad del ciudadano ${ }^{5}$. Esos derechos protegen, inmediatamente, el ciudadano en su libertad subjetiva negativa contra interferencias estatales, bien como de intervenciones causadas por otros ciudadanos 6 .

Por otro lado, los derechos de prestación se conciben como derechos positivos ${ }^{7}$, siendo identificados en la concepción de una libertad positiva, una libertad para algo ${ }^{8}$. Aquí, fueron idealizados los derechos fundamentales sociales, consecuentes del Estado Social.

Así, se puede afirmar que los derechos fundamentales sociales exigen, por parte del Ejecutivo y Legislativo, una acción direccionada a su concretización, constituyendo, en obligaciones de

\footnotetext{
${ }^{4}$ Cara destaca que "los derechos fundamentales son obra de la revolución americana. Los colonos americanos reaccionaron oponiendo estos derechos al característico déficit de los derechos de libertad ingleses, anclados exclusivamente en el plano de la ley ordinaria y que, por tanto, no constituían defensa alguna contra las limitaciones de la libertad decididas en el parlamento", Grimm (2006), p. 158.

${ }^{5}$ Alexy (1994), pp. 233-235.

${ }^{6}$ Kirste (2013), p. 167.

${ }^{7}$ Alexy (1994), p. 238.

${ }^{8}$ Kirste (2018), p. 165.
} 
prestación positivas cuya satisfacción consiste en un facere, una acción positiva a cargo de los Poderes Públicos ${ }^{9}$ —lo que transcurre, a la vez, a su protección en el orden de derechos objetivos, como se verificará-. Dotados de un carácter prestacional, los derechos sociales se presentan, de esa manera, como sinónimos de una "pretensión de prestación estatal, implicando acciones de los poderes públicos para dar respuesta a dicha pretensión"10.

Para volver clara la diferencia y contrapunto de los derechos de defensa y derechos de prestación, oportuna es la concepción de Leal11, cuando trabaja la dignidad de la persona humana como criterio para el control jurisdiccional de políticas públicas, afirmando que los derechos positivos (prestacionales), se diferencian significativamente de aquellos tenidos como negativos (de defensa o de abstención), pues, cuando algo es prohibido, como es el caso de los últimos, entonces toda y cualquier acción que implicar una violación del derecho protegido es tenida como prohibida. Sin embargo, cuando algo es impuesto en una dimensión positiva, ni toda y cualquier acción que protege o promueve el derecho es tenida como debida, abriéndose espacio, entonces, para una ponderación (entre medios y fines), a cuál, en esfera administrativa, se traduce en concepto de discreción.

Ocurre, no obstante, que esas concepciones no pueden ser cerradas, porque, de un derecho de defensa (negativo), se concibe la derivación de una dimensión positiva, como de un de derecho prestacional (positivo) una dimensión negativa. En ese entendimiento, se concluye que los derechos fundamentales poseen una función doble negativa y positiva, al hecho de que no se debe identificar los derechos sociales como "positivos" y los derechos de libertad como "negativos", por poseer criterios distintos de análisis y de clasificación12.

De esa forma, muchos autores defienden la no realización de una distinción y sí el reconocimiento del carácter multifuncional de los derechos fundamentales sociales, lo que se aboga aquí, o sea, una función de defensa (negativa) y una función de prestación (positiva), que no se excluyan, pero se complementen al mismo tiempo. Hay una doble cualificación a los derechos fundamentales, incluyendo, los sociales.

Por ejemplo, el derecho a vivienda, derecho social, en la condición de derecho a acciones positivas, carece de la promoción y satisfacción de necesidades materiales; y, al revés, también

\footnotetext{
${ }^{9}$ Queiroz (2006), p. 16.

${ }^{10}$ Gavara De Cara (2010), p. 11.

${ }^{11}$ Hennig Leal (2014), p. 145.

12 Wolfgang Sarlet (2015), p. 211.
} 
es protegido contra injerencias externas, como es el caso del derecho de inviolabilidad de domicilio frente al Estado y particulares ${ }^{13}$. Lo mismo ocurre con el derecho a huelga, el cual se traduce en un derecho a omisión ${ }^{14}$.

Con tal reconocimiento, ocurre la superación de la noción de que algunos derechos demandan apenas una abstención por parte del Estado, cuando también exigen de los Poderes Públicos prestaciones normativas y fáticas, evitando, en ese sentido, la violación de derechos fundamentales. Además, propician la creación de instrumentos procesuales o procedimientos adecuados a su defensa y garantía 15 .

A lo que se refiere a la estructura constitucional brasileña, esos derechos poseen posición que revela su importancia y que indica la necesidad de estructurar la aplicación de las normas del ordenamiento jurídico. Diferente de muchos países europeos, pudiéndose citar Alemania y Austria, los derechos sociales, con la Constitución de 1988, recibieron carácter fundamental, de esa manera, la Constitución brasileña además de prever expresamente la existencia de derechos fundamentales sociales (art. 6ํㅜ), especificando su contenido y forma de prestación (arts. 196, 201, 203, 205, 215, 217, entre otros), no hace distinción entre los derechos y deberes individuales y colectivos (Capítulo I do Título II) y los derechos sociales (Capítulo II do Título II), al establecer que los derechos y garantías fundamentales tienen aplicación inmediata (CF/88, art. $\left.5^{\underline{o}}, \S 1^{\stackrel{o}{ }}\right)^{16}$.

Con eso, se observa que "se constitucionalizaron catálogos más o menos amplios de derechos económicos sociales y culturales — derechos esos que, contrariamente a los derechos a la libertad, no son meros poderes de actuar, pero de exigir"17, lo que hace con que "la aparición de los derechos sociales ha supuesto una notable variante en el contenido de los derechos fundamentales"18.

Aún, con Hesse, el reconocimiento de los derechos fundamentales como derechos sociales:

influyen en todo el Derecho [...] no sólo cuando tiene por objeto las relaciones jurídicas de los ciudadanos con los poderes públicos, sino también cuando regula las relaciones jurídicas entre los particulares. En tal medida sirven de pauta tanto para el legislador como para las demás

\footnotetext{
13 Wolfgang Sarlet (2015), p. 211.

${ }^{14}$ Leivas (2006), p. 88.

${ }^{15}$ Queiroz (2006), p. 22.

16 Mendes (2012), p. 483.

${ }^{17}$ Hennig Leal (2007), p. 16, traducción nuestra.

18 Pérez (2013), p. 22. Destaca Queiroz, aún, que "será, no obstante, en los años 70 del siglo XX, que se colocará con mayor acuidad la cuestión de saber cuánto a esos derechos si los mismos poseen status constitucional", Queiroz (2006), p. 16, traducción nuestra.
} 
instancias que aplican el Derecho, todas las cuales al establecer, interpretar y poner en práctica normas jurídicas habrán de tener en cuenta el efecto de los derechos fundamentales ${ }^{19}$.

Por fin, verificada la multifuncionalidad de los derechos fundamentales sociales, cabe averiguar su forma de justiciabilidad, sea en el orden de derechos objetivos - característica fuertemente identificada a los derechos fundamentales sociales-, o de derechos subjetivos, visión más tímida y criticada, y, por veces, no reconocida.

\section{La tutela jurisdiccional de los derechos fundamentales sociales}

La protección primaria, o clásica, de los derechos fundamentales sociales es de carácter objetivo, de protección por los Poderes Legislativo o Ejecutivo, o sea, no de incumbencia del Poder Judiciario. De esa manera, esos derechos implican en una lectura de derechos en términos de colectividad y no de singularidad, lo que impediría una defensa subjetiva (individual), ante el Poder Judiciario 20.

En virtud de esa vinculación y de la necesidad de actuación de los Poderes para la concretización y promoción de derechos fundamentales sociales, la forma de infracción más común a su contenido - $-\mathrm{y}$, consecuentemente, a la Constitución-, es la omisión de los Poderes del Estado 21 , una vez que hay la "obligación del Estado en adoptar medidas positivas de la más diversa naturaleza con el objetivo precipuo de proteger de forma efectiva el ejercicio de los derechos fundamentales"22. Se configura en el deber de protección estatal a los derechos fundamentales sociales, oriundo, propiamente, de la dimensión objetiva de los derechos fundamentales ${ }^{23}$.

\footnotetext{
${ }^{19}$ Hesse (1996), p. 93.

${ }^{20}$ Cuanto a los derechos sociales, “[...] implica una lectura implícita de los derechos en términos de colectividad, es decir, el impulso que genera los bienes jurídicos protegidos (por ejemplo, medio ambiente, asistencia social o educación) se debe interrelacionar con la necesidad de su protección preferente en términos de medidas que sean aplicables a la generalidad de los supuestos y no como un acceso global basado en la individualidad o singularidad que puede implicar una posición jurídica subjetiva. En este sentido, su defensa y protección requiere normas objetivas con un alcance afectivo de su cumplimento real en términos de lo políticamente posible, es decir, con condiciones y requisitos objetivos de su ámbito de protección, y no una defensa subjetiva para todos los individuos sin concreción objetiva de su alcance", Gavara De Cara (2010), p. 13.

${ }^{21}$ Gavara De Cara (2010).

22 Wolfgang Sarlet (2010), p. 113, traducción nuestra. Gilmar Mendes destaca, en ese sentido, la existencia de un "postulado de protección (Schutzgebote). Habría así [...] no apenas una prohibición de exceso (Übermassverbot), pero también una prohibición de protección insuficiente (Untermassverbot)", Mendes (2012), p. 464.

23 La dimensión objetiva de los derechos fundamentales fue concebida por el Tribunal Constitucional alemán (Bundesverfassungsgericht) en la decisión del caso Lüth, de 1958, de la cual recurren algunos aspectos importantes: a) la irradiación (Ausstrahlungswirkung) de efectos de los derechos fundamentales en todos los sectores del derecho (constitucionalización), incluso en las relaciones de derecho privado, denominada eficacia contra terceros (Drittwirkung); b) las garantías procesuales de los procesos de decisión que pueden llevar perjuicio a los derechos fundamentales; c) el principio de organización y procedimiento de las instituciones públicas y privadas; y, tal vez lo más importante, d) el deber de protección estatal (Schutzpflicht) en las libertades aseguradas por derechos fundamentales, Grimm (1991), p. 221.
} 
Esa intervención estatal demanda un planeamiento por parte del ente de forma a comprender la realización de una gama de derechos garantizados constitucionalmente, los cuales, a la vez, tienen sus costos (a pesar de los derechos de libertad también poseer su costo), solo pudiendo ser garantizados "a la medida de lo posible", es decir, de modo proporcional al desarrollo y al proceso económico y social24.

Uno de los argumentos frecuentemente invocados se refiere, específicamente, a esa problemática que transcurre de la garantía de lo mínimo existencial frente a la reserva de lo posible ${ }^{25}$, una vez que la concretización de los derechos presentes en ese mínimo implica, inevitablemente, costos y exige previsiones de presupuesto que los contemplen. Radica en esa cuestión una de las dificultades en la realización de los derechos fundamentales sociales. Importante realzar que, en Brasil, la reserva de lo posible es relacionada con la escasez de recursos, no siguiendo el origen alemán ${ }^{26}$ de la teoría, por la cual "se encuentra sujeto a la reserva de lo posible, en el sentido de aquello que el individuo puede esperar, de manera racional, de la sociedad. 0 sea, la argumentación adoptada se refiere a la razonabilidad de la pretensión" 27 y no solo a los costos envueltos 28 .

En esas consideraciones, se busca verificar si los derechos fundamentales sociales son derechos subjetivos, que conciben al individuo un poder de actuar jurídicamente para la imposición de sus intereses, defendiéndose de acciones practicadas por el Estado o por otros ${ }^{29}$, es decir, la posibilidad de que esos derechos sean demandados judicialmente y requeridos, incluso de forma individual, frente al Estado y/o si sobre ellos solo recae una protección de cuño objetivo, de protección por los Poderes Legislativo o Ejecutivo.

Los derechos subjetivos, se esclarece, "son protegidos por las Constituciones como derechos fundamentales y, en tratados internacionales, como derechos humanos. En cuanto tales, obligan

\footnotetext{
${ }^{24}$ Queiroz (2006), p. 25.

25 También Pérez destaca que son utilizadas "expresiones tales como la de 'el condicionamiento fiscal', o la 'reserva económica de lo posible', para negar, supeditar, limitar o aplazar la satisfacción de los derechos sociales", Pérez (2013), p. 18). Aún, sobre la concepción brasileña de la teoría de la reserva de lo posible, ver Leal y Maas (2019): “Políticas públicas y el 'fuzzysmo' de la efectividad de los derechos fundamentales sociales: análisis crítico del Are 639.337/STF- acceso a educación".

${ }^{26}$ En decisión del Tribunal Constitucional Alemán (BverfGE № 33, S. 333), conocida como Numerus Clausus, en un trabajo que versaba sobre posible aumento del número de vagas ofertadas por una universidad.

${ }^{27}$ Mânica (2008), p. 99, traducción nuestra.

${ }^{28}$ Es posible afirmar, frente a esa inevitable relación con los costos, que los derechos fundamentales sociales "se sitúan bajo reserva de lo políticamente posible, es decir, los derechos sociales se deben proteger en la medida en que se produzca una adecuación del estándar social a la situación económica y a la capacidad de prestación económica de un Estado", Gavara De Cara (2010), p. 58.

${ }^{29}$ Kirste (2013), p. 164.
} 
no solamente el Estado a su observancia, pero pueden ser también demandados judicialmente en caso de lesión de ese deber"30.

El camino que se trilla, de esa forma, es el reconocimiento a los derechos fundamentales sociales una vertiente subjetiva, que permite su justiciabilidad individualizada y que se muestra un fenómeno crecente en los últimos años, especialmente en Brasil (diferente de países europeos, como Alemania y Austria que no reconocen esa posibilidad), por los grandes índices de demandas envolviendo el derecho a salud ${ }^{31}$.

En ese sentido, decisión importante acerca de la temática en Brasil relacionada a las Suspensiones de Tutela Anticipada 175, 211 y 278; Suspensiones de Seguranza 3724, 2944, 2361, 3345 y 3355; y Suspensión de Liminar 47. El Supremo Tribunal Federal, en esa oportunidad, dejó asentado que no restringe la judicialización de la salud a la dimensión colectiva, afirmando que del artículo 196 de la Constitución Federal es posible identificar un derecho individual y colectivo a salud, concluyendo por el derecho a salud como un derecho subjetivo, de dimensión individual ${ }^{32}$ y colectiva ${ }^{33}$.

La dimensión subjetiva de los derechos fundamentales sociales sigue siendo afirmada por la doctrina como forma de potencialización de la efectuación de derechos de índole naturalmente colectiva, siendo reconocido que citados derechos poseen tanto una dimensión objetiva, como una dimensión subjetiva.

\footnotetext{
${ }^{30}$ Kirste (2013), p. 165.

${ }^{31}$ En noticia del Tribunal de Contas da União (TCU), de 2017, se tuvo como titular: “Aumentan los gastos públicos con judicialización de la salud", visto que, en siete años, los gastos con procesos judiciales de la União aumentaron $1.300 \%$, siendo que el forne cimiento de medicinas, algunos inclusive sin registro en el Sistema Único de Salud, o sea, sin previsión en la lista de dispensación de medicamentos, corresponde al 80\% de las acciones judiciales. Entre los Tribunales Estaduales con mayor número de procesos, están São Paulo, Rio Grande do Sul y Minas Gerais (Brasil, 2017, https://bit.ly/3a9qUjK), traducción nuestra.

32 La dimensión individual del derecho a salud ya había sido destacada por el ministro Celso de Mello, relator de la AgR-RE 271.2868/RS, antes mismo de la decisión marco de la salud, al reconocer el derecho a salud como un derecho público subjetivo asegurado a la generalidad de las personas, que conduce el individuo y el Estado a una relación jurídica obligacional (Brasil, 2000, http://www.stf.jus.br).

${ }^{33}$ Y esa es una gran crítica en lo que concierne a la judicialización de la salud, o sea, la enorme incidencia de demandas individuales. (Barroso, 2008, https://bit.ly/3c5deYc) afirma que la actuación de la judicialización de esa manera pone en riesgo la propia continuidad de las políticas públicas de salud, eso porque desorganiza la actividad administrativa e impide el destino racion al de los escasos recursos públicos, impidiendo que políticas públicas colectivas, dirigidas a la promoción de la salud pública, sean debidamente implementadas. Sería el caso del exceso de judicialización no llevar a la realización práctica de la Constitución Federal, pues, en muchos casos, se estaba concediendo privilegios a algunas personas en detrimento de la generalidad de la ciudadanía, que continua dependiente de las políticas públicas universales. El resultado sería la realización de una micro justica y no de una macro justica. Preocupado en resolver los casos concretos, el juez no puede olvidarse de la existencia de recursos escasos, limitados, para demandas ilimitadas. Sin embargo, esa no es la posición de toda la doctrina sobre el asunto, Figueiredo y Sarlet (2009), pp. 20-21. Afirman que es preciso recordar que el derecho a salud es, antes de todo y también, un derecho de cada persona, al estar íntimamente conexo a la protección de la vida, de la integridad física y corporal y de la propia dignidad inherente a cada se r humano. De esa manera, la tutela individual no podrá ser desconsiderada, reforzando, aún, la garantía constitucional fundamental del acceso a la jurisdicción, motivo por lo cual no están de acuerdo con la tesis que refuta de modo absoluto las demandas materiales de carácter individual en el ámbito da concreción del derecho a salud.
} 
En ese sentido, Alexy ${ }^{34}$ defiende que, por la importancia de las disposiciones de los derechos fundamentales sociales, la opción de garantizarlos no podría quedar solo en las manos del legislador, de una mayoría parlamentar simple, pues el Tribunal Constitucional no puede dejar de actuar debido a un legislador omiso ${ }^{35}$, llegando al punto de formular un enunciado general de los derechos a prestaciones ${ }^{36:}$ "Jeder befindet sich aufgrund von Grundrechtsnormen in den leistungsrechtlichen Positionen, die vom Standpunkt des Verfassungsrechts aus so wichtig sind, da $\beta$ ihre Gewährung oder Nichtgewährung nicht der einfachen parlamentarischen Mehrheit überlassen werden kann”. En conexión, el margen de apreciación legislativa no garante, pues, la no realización de un derecho, no pudiendo servir como una excusa a los deberes legislativos de garantía de derechos reconocidos constitucionalmente como derechos fundamentales, como son, en Brasil, los derechos fundamentales sociales - refiriéndose a formas de actuación y no a la omisión.

Se observa que, al lado de autores abogando por la no-justiciabilidad ${ }^{37}$ de los derechos fundamentales sociales en la doctrina alemana, pudiéndose citar Ernst-Wolfang Böckenforde (1992) y Konrad Hesse (1994), justamente por el hecho del legislador, que es el legitimado democrático para ese fin, no atribuir esa obligación al Estado, Alexy defiende en sentido contrario, o sea, frente a un legislador omiso, un Judiciario activo.

Sin embargo, Alexy ${ }^{38}$ afirma que, cuando presenta el argumento de la competencia de los derechos fundamentales sociales en virtud de sus efectos financieros, por consecuencia de los grandes costos asociados a su realización, conduciría, inclusive, a que la política de presupuesto quedaría en manos del Tribunal Constitucional, lo que sería incompatible con la Ley Fundamental. Además, es lo que se enfrenta en Brasil, principalmente en respeto a la salud, donde, frente a la ineficacia u omisión de políticas públicas, bien como en razón de inúmeros otros factores, el Poder Judiciario se vuelve el realizador del derecho fundamental a la salud,

\footnotetext{
${ }^{34}$ Alexy (1994), p. 465.

${ }^{35}$ Alexy (1994), p. 465. Afirma que tal concepción debe ter en cuenta el equilibrio entre el principio de libertad fática, frente a los principios formales de la competencia decisoria del legislador democráticamente legitimado y el principio de la separación de poderes, además de principios materiales que dicen respeto a la libertad jurídica de terceros, como otros derechos fundamenta les sociales e intereses colectivos. De esa forma, no trae tal alternativa como definitiva, pero que debe ser verificada caso a caso, frente a cada derecho fundamental social.

${ }^{36}$ Alexy (1994), p. 410.

${ }^{37}$ Se entiende necesario realizar la diferencia entre justiciabilidad, que comprende la posibilidad de la demanda judicial en la exigencia de determinados derechos, y judicialización, fenómeno de ampliación de competencias del Judiciario en la garantía de derechos, en la medida en que son conceptos que se aproximan, pero que no se confunden.

${ }^{38}$ Alexy (1994), p. 462.
} 
ultrapasando, muchas veces, el gasto con judicialización de la salud el propio presupuesto del ente estatal para ese fin $^{39}$.

No obstante, la apreciación de los factores económicos para la tomada de decisión con relación a las posibilidades y los medios de efectuación de esos derechos fundamentales sociales cabe, principalmente, a los órganos políticos y legislativos ${ }^{40}$. Además, es el Poder Legislativo el primero a realizar la interpretación y concretización de esos derechos, cabiendo a ellos las elecciones asignativas y la definición de políticas públicas.

De esa forma, "un determinado derecho fundamental investirá su titular en diversas posiciones jurídicas de caracteres diferenciados, y con base en cada una de ellas, el ciudadano podrá reclamar diferentes obligaciones del Poder Público" 41 , sin una restricción de su forma de tutela, permitiendo una vertiente de posibilidades. Por su complejidad, los derechos fundamentales sociales se configuran como:

derechos subjetivos y elementos fundamentales de orden constitucional objetiva. En cuanto derechos objetivos, los derechos fundamentales otorgan a sus titulares la posibilidad de imponer sus intereses frente a los órganos obligados. En su dimensión como elemento fundamental del orden constitucional objetivo, los derechos fundamentales - tanto aquellos que no aseguran, primeramente, un derecho subjetivo cuanto aquellos otros, concebidos como garantías individuales - forman a base del ordenamiento jurídico de un Estado de Derecho democrático ${ }^{42}$.

Por constituir como la base del ordenamiento jurídico, la vinculación de los Poderes del Estado a la concretización de estos postulados es reforzada, siendo expresa constitucionalmente. Cabe comprender, en ese sentido, el espacio de margen legislativa permitida delante de la complejidad de las formas de tutela y de las características de la función prestacional de los derechos fundamentales, como será ahora analizado.

\section{El reconocimiento de un margen de apreciación del legislador en la efectuación de derechos fundamentales sociales}

\footnotetext{
39 Por ejemplo, se tiene los Estados de São Paulo, Minas Gerais y Santa Catarina que despenderán, juntos, con demandas judiciale s, entre 2013 y 2014, R\$ 772 millones, valor superior al gasto de la Unión en el mismo período (Conselho Nacional de Justiça, 2017, https://bit.ly/3ad0I7X). En complemento, efectuado estudio online a través del Painel Justicia en Números, considerando las acciones correlacionadas al tema de la salud ajuiciadas en el período de 01 de enero de 2014 (fecha de implementación del panel) a 31 de diciembre de 2018 (fecha de la última actualización del panel), fueron constatadas 2.144 .359 acciones envolviendo el derecho a la salud. De ese número, 1.004.305 acciones se atribuyen al fornecimiento de medica mentos y de tratamientos médicohospitalario (Conselho Nacional de Justiça, 2019, https://bit.ly/2Rwk29L), lo que demuestra la gran demanda por ese derecho en Brasil.

${ }^{40}$ Leivas (1999), p. 241.

${ }^{41}$ Hachem (2014), p. 292.

42 Mendes (2012), p. 468, traducción nuestra.
} 
La Constitución Federal brasileña trae expresamente la vinculación de los tres Poderes del Estado a la concretización de los derechos fundamentales ${ }^{43}$, sea a través de una acción —como la implementación de políticas públicas o reglamentación normativa - o de una abstención, en el sentido de no intervención y no de omisión. En ese contexto, hay que considerarse la existencia de una división de competencias entre los Poderes, la cual trae consigo una noción de equilibrio y armonía en la relación entre ellos, con pesos y contrapesos, por medio de la cual un Poder no debe interferir en la esfera de actuación destinada inicialmente a otro.

Delante de esa situación, cabe cuestionar cual es el espacio de actuación del legislador frente a esa vinculación y la relación de control establecida con los demás Poderes, especialmente a partir de la noción de la Constitución para más allá del texto escrito, como convicción ${ }^{44}$. Con la caracterización de un Estado Democrático de Derecho, o "control del órgano legislativo en respecto a la garantía institucional corresponde a los órganos encargados de hacer efectiva la supremacía constitucional, Tribunal Constitucional y Tribunales de Justicia"45, haciendo con que el análisis de eventuales omisiones legislativas esté a cargo del Poder Judiciario. Se evidencia, en ese sentido, la relación Legislativo y Judiciario, la cual refuerza la estructura de protección destinada a los derechos fundamentales sociales que, como referido, detiene una importancia impar, que no permite que sean dejados solo en las manos de mayorías legislativas —en el orden de un legislador omiso, un Judiciario activo.

El Supremo Tribunal Federal brasileño no trae una discusión con profundidad acerca de la margen de apreciación del legislador en relación a los derechos sociales. En reciente decisión, acerca del costeo de medicaciones no reguladas por la Agência Nacional de Vigilância Sanitária (ANVISA), proferida en el año 2019, en lo Recurso Extraordinario № 657718, se trató de la excesiva judicialización del derecho social a la salud y el rol del Supremo Tribunal en la concreción de derechos sociales por esa vía y los retos envolviendo el mínimo existencial e la reserva del posible, bien como a la naturaleza del derecho a la salud en cuanto derecho social 46 . Aunque las manifestaciones de los ministros tengan echo referencia a una necesidad de

\footnotetext{
${ }^{43}$ Se extrae la vinculación en algunos dispositivos, entre ellos: art. 4o, p. ú., alinea "c", de la Ley 8.069/90 (preferencia en la formulación de Políticas Sociales Públicas específicas); art. 5o y siguientes, de la Ley Complementar n. 141/2012 (valores mínimos a ser aplicados anualmente en acciones y servicios públicos de salud), bien como dispositivos encontrados en la Constitución Federal, cuales sean: art. 195 (financiamiento de seguridad social), art. 198, § 2o (recursos mínimos de aplicación en las acciones direccionada a la salud), art. 211 (vinculación a los regímenes de enseñanza en la promoción de la educación), art. 212, "caput" (porcentuales a ser aplicados en la manutención de la educación), entre otros.

${ }^{44}$ Zagrebelsky (2014).

${ }^{45}$ Nogueira (2000), p. 74.

${ }^{46}$ Brasil, Supremo Tribunal Federal, Recurso Extraordinário № 657718, de 22 de maio de 2019.
} 
autocontención del Poder Judicial y de deferencia a el Poder Público y su espacio de decisión, el mérito de la acción es juzgado y no son traídas discusiones al rol del legislador.

Incluso, destaca el ministro Alexandre de Moraes la inducción de pautas legislativas por parte del Poder Judicial brasileño:

na última década e meia, inclusive, pela essencial construção pretoriana realizada por nossa Corte, pelo Supremo Tribunal Federal, houve acentuada evolução legislativa e normativa também, por parte do Executivo, no sentido de equacionar o problema, com a construção séria e concreta de uma gestão de políticas públicas no setor de saúde ${ }^{47}$.

Así, mismo con el debate acerca del rol judicial y de las referencias a la falta de expertise y capacidad institucional del Poder Judicial en decisiones que involucran derechos sociales y políticas públicas, el margen de apreciación del legislador solo era citado cuanto a su primacía en la creación de políticas públicas ${ }^{48}$.

El modelo de separación de Poderes hoy existente fue estructurado y pensado para una organización estatal y social distinta de la actual, en la cual las funciones del Estado se centraban básicamente en la manutención del orden, de la defensa estatal y en la producción penal ${ }^{49}$. Un modelo, por tanto, restricto, que conforma una teoría basada en la de Montesquieu - que sistematiza las funciones del Estado analizadas por Aristóteles, siendo ellas las funciones deliberativa, ejecutiva y judicial ${ }^{50}$ - dejando de lado perspectivas abordadas por otros autores, como Locke y Kant.

Con la relación de pesos y contrapesos que se establece y con la supremacía de la Constitución, adoptada con el Estado Democrático de Derecho, la libertad legislativa se vuelve limitada. El sistema idealizado por Madison51 apuesta, como critica Gargarella (2014), en mecanismos de control endógenos, pautados en una confianza acerca de las capacidades de decisiones de los Poderes, por medio de sus funcionarios, y no en virtudes de la sociedad, comprometida con sus intereses sociales. Hay, así, una necesidad de articulación de los tres Poderes y el reconocimiento, por parte de cada uno de ellos, de sus respectivos espacios de actuación.

\footnotetext{
${ }^{47}$ Brasil, Supremo Tribunal Federal, Recurso Extraordinário № 657718, de 22 de maio de 2019, p. 117.

${ }_{48}$ Brasil, Supremo Tribunal Federal, Recurso Extraordinário № 657718, de 22 de maio de 2019.

${ }^{49}$ Ferrajoli (2008).

50 Saddy (2009).

${ }^{51}$ En cuanto al desarrollo de la jurisdicción constitucional y formas de control de constitucionalidad, ver Leal (2007), "Jurisdicción constitucional abierta: reflexiones sobre la legitimidad y los límites de la jurisdicción constitucional en el orden democrático - un abordaje a partir de las teorías constitucionales alemana y norteamericana".
} 
La vinculación del legislador a las normas constitucionales lo condiciona, de ese modo, la no edición de "normas que dispongan contrariamente a las normas constitucionales atributivas de derechos sociales. Y ni siquiera puede revocar ley que dé viabilidad a una de esas normas constitucionales sin emitir nueva ley"52. Hay una significativa limitación de la actuación legislativa, no siendo su espacio de actuación un espacio ilimitado, a ser reconocido, primariamente, por el propio Poder Legislativo, también responsable por la realización de un control de constitucionalidad de las normas.

De un punto de vista material no es, por lo tanto, ilimitada, pues hay una vinculación constitucional del legislador con la observancia de parámetros para la garantía de derechos fundamentales, siendo la noción de "margen de acción" definido por una ausencia de esa vinculación legal ${ }^{53}$. El punto central de discusión sobre el margen de apreciación legislativa se encuentra en la pregunta: ¿pueden los Tribunales, en ejercicio del control de constitucionalidad, interferir en el espacio de conformación legislativa, en el margen de apreciación del legislador, o ese es libre?54.

Por tanto, decir que el margen legislativo sea ilimitado es sustentar, de mismo modo, la ausencia de vinculación del legislador a los contenidos establecidos en la Constitución Federal brasileña, contrariando el marco jurídico existente. No se trata, así, de cuestionar se hay un espacio ilimitado o no, sino de buscar establecer parámetros que coadunen la actuación legislativa, en su libertad de acción, con la protección y concretización de derechos fundamentales sociales.

Necesario diferenciar, en ese sentido, la decisión de no actuar del legislador, que viola derechos fundamentales y, por tanto, debe ser apreciada por el Poder Judiciario en la realización de un control de constitucionalidad (debido a una inconstitucionalidad por omisión), de la decisión de actuar que permite un margen de elección en lo que toca a algunos elementos como referente a la creación de una política pública, por ejemplo. En ese sentido, derechos sociales como el derecho a salud y educación, no podrían — delante de la importancia de la Constitución Federal y en la conformación de derechos fundamentales sociales-, ser colocados

\footnotetext{
52 Miranda (1986) p. 124, traducción nuestra.

${ }^{53}$ Queiroz (2006).

${ }^{54}$ Queiroz (2006).
} 
a margen de la libre apreciación de los Poderes Legislativo y Ejecutivo sin que hubiese, al menos, la posibilidad de intervención judicial cuando esos fueren omisos en su efectuación ${ }^{55}$.

Dicha margen de apreciación del legislador con relación a los demás Poderes del Estado se difiere del margen de apreciación nacional existente en relación entre Corte Internacionales, como la Corte Interamericana de Derechos Humanos, y los Estados, pudiendo la segunda ser definida como "una actitud judicial de deferencia hacia las autoridades internas, al estar ubicadas en una mejor sede para el enjuiciamiento de ciertos conflictos de intereses y responder democráticamente ante sus electorados" 56 . En cuanto al margen nacional, cabe cuestionar "¿cuál es la línea divisoria entre las decisiones de política económica y social (supuestamente fuera del escrutinio de los órganos internacionales) y las violaciones a los derechos humanos económicos, sociales y culturales [...]?", esos sí englobados por un margen de evaluación de los órganos judiciales internacionales ${ }^{57}$.

A lo que se refiere al margen interno de apreciación del legislador, la cuestión concebible se relaciona con la línea entre decisiones reservadas constitucionalmente como siendo de primacía del legislador y decisiones que, sobre todo, consideran la violación de derechos fundamentales, permitiendo una intervención judicial. De ese modo, es interesante observar que, aunque en muchas cuestiones haya referida primacía legislativa, no necesariamente

el principio de la competencia decisoria del legislador pueda prevalecer en todos los casos y circunstancias sobre el principio material de la protección de los derechos fundamentales. La respuesta a esta cuestión está en un procedimiento de ponderación que respete una delimitación jurídico-funcional adecuada entre el margen de acción del legislador, reconocido constitucionalmente, y la vinculación del legislador a los derechos fundamentales ${ }^{58}$.

Delante de esa vinculación, los derechos fundamentales - y humanos, a lo que se refiere al nivel internacional— actúan como límites materiales y sustantivos a actividades del legislador 59 , restringiendo el campo de actuación legislativa, el cual no comporta una omisión indiscriminada, pero "compromete derechos humanos [y fundamentales], vulnerando su exigibilidad y cumplimiento en específico, al grado de producir una afectación, daño o perjuicio"60. Importante realzar que, la pura y simple omisión legislativa no está amparada por el margen de apreciación del legislador, pues la violación de derechos fundamentales puede darse en una perspectiva

\footnotetext{
55 Bitencourt (2013), traducción nuestra.

56 García (2007), p. 142.

${ }^{57}$ Aguilar (2012), p. 244.

${ }^{58}$ Queiroz (2006), p. 51.

${ }^{59}$ Nogueira (2012).

${ }^{60}$ Lazcano, Cárdenas y Torres (2017), p. 230.
} 
doble: sea por la edición de leyes contrarias a su efectuación o por la mera omisión del legislador61.

En esos casos, cuando hay una evidente omisión del legislador, violando las vinculaciones constitucionales a la concreción de derecho fundamentales, “"el control del órgano legislativo en el respecto a la garantía institucional corresponde a los órganos encargados de hacer efectiva la supremacía constitucional, Tribunal Constitucional y Tribunales de Justicia"62. Así, se establece una prevalencia de la norma sobre los derechos, orientando la actuación de los poderes a partir de una lógica de "prefered rights position"63.

Todavía, es necesario tener en cuenta que en muchos casos hay una preferencia del legislador determinada en la Constitución, como en el caso de la creación de políticas públicas, no debiendo los tribunales ocuparen los espacios del representante popular. De todas las formas, la vinculación del legislador a los derechos fundamentales y a la Constitución como un todo, limitan su margen de acción, la cual es definida como la "ausência de qualquer tipo de vinculação jurídico material"64.

En lo espacio de mayor manobra el legislador es libre para decidir sobre cuestiones puntuales como las que involucran el presupuesto, o metas y objetivos de la norma, pero, así mismo, partiendo de las bases y los límites internos y externos de los derechos fundamentales sociales. El contenido esencial de los derechos configurase como un verdadero parámetro de definición de los contenidos de derechos sociales y no puede, de forma alguna, ser afectado por la actuación del legislador ${ }^{65}$, que debe mirarlos.

Por tanto, es imperioso el reconocimiento de la vinculación del legislador la concretización de derechos fundamentales de cuño social, en cambio, hay que tenerse presente también la existencia de un margen de apreciación que contemple la tomada de decisiones — de carácter fático o normativo- que envuelva algunos aspectos relativos a tal concretización. Con todo, aunque presentes cuestiones relacionadas con los costos acarreados al Estado que son directamente relacionados con los derechos fundamentales sociales ${ }^{66}$, es imperioso reconocer

\footnotetext{
${ }^{61}$ Lazcano, Cárdenas y Torres (2017).

${ }^{62}$ Nogueira (2000), p. 74.

${ }^{63}$ Nogueira (2000).

${ }^{64}$ Queiroz (2006), p. 12.

65 Petit Guerra (2017).

${ }^{66}$ En ese sentido, ver las discusiones acerca de la vinculación de los derechos fundamentales sociales y de la manutención de un Estado de Bien-Estar Social a los tributos y la necesidad de reformulación de algunas estrategias de recaudación, traídas en Holmes y Sunstein (2000), "The cost of rights: Why Liberty Depends on Taxes", y Piketty (2014), "O capital no século XXI”.
} 
que "nadie se limita bien a sí mismo si no se ha asentado una división de poderes, tampoco los tribunales"67.

Delante de esto, hay que se cuestionar si "nessa "margem de acção" o legislador é livre ou se nela podem intervir ainda os tribunais de justiça constitucional no exercício de seu direito de controle" 68 , cuestión que, en mucho, demanda una trabajosa argumentación que demuestra la violación de eso núcleo esencial de la Constitución y en las bases de los derechos fundamentales sociales por parte del legislador.

La intervención judicial es, frente a las premisas presentadas, posible. Entendiendo ese que fueron mantenidas las promesas constitucionales y su vinculación a los contenidos esenciales, cabe al legislador traer a la arena jurídico-política sus argumentos y invocar la teoría que sustenta su margen de apreciación en el ejercicio legislativo y, analizadas por el Poder Judicial, por ese reconocidas.

Sin embargo, cuanto más intensa sea referida intervención del Poder Judiciario, en el ejercicio del control jurisdiccional, en el espacio de actuación de los Poderes Legislativo y Ejecutivo, más cuidadosa y justificada debe ser esa intervención judicial ${ }^{69}$. Debe presentarse dentro de límites que mantengan la deferencia en la relación entre los Poderes, especialmente a lo que se refiere a algunas decisiones de políticas estructurales que se encuentran en el proceso de efectuación de los derechos fundamentales sociales.

\section{Conclusión}

El reconocimiento de la multifuncionalidad de los derechos fundamentales se incluye, aquí, los sociales, hace con que ellos necesiten ser llevados en serio en su concretización, en el orden de derechos negativos y/o positivos. En Brasil la vinculación de los tres Poderes del Estado a esos postulados de orden constitucional permite que sean prontamente exigibles y que haya una fiscalización recíproca en cuanto a esa vinculación, garantiendo al particular y acceso a los derechos sociales, por su propia característica consolidada en los Tribunales de derecho subjetivo.

${ }^{67}$ García (2007), p. 125.

${ }^{68}$ Queiroz (2006), p. 12.

${ }^{69}$ Queiroz (2006) y Klatt (2015). 
De esa manera, la certificación de la existencia tanto de una justiciabilidad de carácter objetiva como subjetiva, garante distintas formas de concretización y efectuación de los derechos fundamentales sociales, lo que, de un lado y de otro, asevera la crítica a la actuación del Poder Judiciario. La efectividad de esos derechos deja, así, de guardar relación solo de protección a los derechos en orden de carácter objetivo, de tarea de los Poderes Legislativo y Ejecutivo, y pasa a ser pasible de demanda subjetiva, lo que es pacífico en orden jurídica brasileña, pero ni tanto en otros países, como, por ejemplo, en Alemania.

Delante de esas características, respondiendo al problema de investigación propuesto, es posible afirmar la existencia de un margen de apreciación del legislador en lo que toca a la realización de los derechos fundamentales sociales, no siendo ella, sin embargo, ilimitada. La vinculación constitucional del legislador a la concretización de los derechos fundamentales se consagra como una limitación del espacio decisorio, estando la efectividad de esos derechos arriba de valoraciones políticas que puedan vaciar su contenido. De ese modo, no es totalmente discrecional la decisión de concretizar derechos fundamentales sociales o mismo la elección de los medios de su realización por parte del Poder Legislativo —debiendo tales elecciones estar amparadas por la Constitución y los principios que la nortean-, confiriendo al legislador un margen de apreciación en cuanto a algunos elementos, desde que no violen al contrario de proteger los derechos fundamentales.

Así, es necesario establecer un punto de equilibrio entre las posibilidades de elecciones existentes en ese margen con la vinculación constitucional que atinge el legislador y la intervención judicial, lo que refuerza las formas de protección de los derechos fundamentales sociales cuando omiso el Poder Legislativo. Hay también la exigencia de una actitud de autocontención judicial por parte del Poder Judiciario cuando la vía legislativa presentarse como la mejor forma de garantía de esos derechos, cabiendo a los órganos juzgadores analizar quienes se encuentran en mejores condiciones de proteger, promover y efectuar los derechos fundamentales sociales.

\section{Bibliografía citada}

Alexy, Robert (1994): Theorie der Grundreche (Frankfurt am Main, Suhrkamp).

Aguilar Cavallo, Gonzalo (2012): “Cuál es la doctrina de la CIDH em materia de derechos econômicos, socieles y culturales?", en Llanos Mardones, Hugo Ignacio; Picand Albónico, 
Eduardo: Estudios de Derecho Internacional: libro homenaje al Profesor Hugo Llanos Mansilla (Santiago, Abeledo Perrot).

Bissoli Lage, Lívia Regina Savergnini (2011): "Políticas Públicas como programas e ações para o atingimento dos objetivos fundamentais do Estado", en Pelegrini Grinover, Ada; Watanabe, Kazuo (Orgs.): O controle jurisdicional de políticas públicas (Rio de Janeiro, Forense).

Borges Mânica, Fernando (2008): "Teoria da Reserva do Possível: direitos fundamentais a prestações e a intervenção do Poder Judiciário na implementação de políticas públicas", en Cadernos da Escola de Direito (№ 08), pp.89-104.

Dalari Bucci, Maria Paula (2006): "O conceito de política pública em direito", en Políticas Públicas: reflexões sobre o conceito jurídico (São Paulo, Saraiva).

Böckenförde, Ernst-Wolfang (1992): Staat, Verfassung, Demokratie: Studienzur Verfassungstheorieund zum Verfassungsrechts (Frankfurt am Main, Suhrkamp).

Conselho Nacional de Justiça (2019): Justiça em números 2019, CNJ, [fecha de consulta: 13 de noviembre de 2019]. [Disponible en: https://bit.ly/3tmgsxa].

(2017): TCU e Estados apontam aumento dos gastos com a judicialização da saúde, CNJ. [Disponible en: https://bit.ly/3wWKny1]. [Fecha de consulta: 13 de noviembre de 2019].

Ferrajoli, Luigi (2008): "La esfera de lo indecidible y la división de poderes", en Estudios Constitucionales: Revista del Centro de Estudios Constitucionales, pp. 337-343.

Filchtiner Figueiredo, Mariana; Wolfgang Sarlet, Ingo (2009): Algumas considerações sobre o direito fundamental à proteção e promoção da saúde aos 20 anos da Constituição Federal de 1988. [Disponible en: https://bit.ly/3tpoFR0].

García Roca, Javier García (2007): "La muy discrecional doctrina del margen de apreciación nacional según el Tribunal Europeo de Derechos Humanos: soberanía e integración", en Teoría y realidad constitucional, (№ 20), pp. 117-143. 
Gargarella, Roberto (2014): “El nuevo constitucionalismo dialógico frente al sistema de los frenos y contrapesos", en Por una justicia dialógica: el Poder Judicial como promotor de la deliberación democrática (Buenos Aires, Siglo Veintiuno).

Gavara de Cara, José Carlos (2010): “La dimensión objetiva de los derechos sociales”, en Cuadernos de derecho Constitucional (Barcelona, Librería Bosh).

Gomes Canotilho, José Joaquim (2004): “Metodologia 'fuzzi' e camaleões normativos”, em Estudos sobre Direitos Fundamentais (Coimbra, Coimbra).

Grimm, Dieter (2006): Constitucionalismo y derechos fundamentales. (Madrid, Trotta). (1991): Die Zukunf der Verfassung (Frankfurt am Main, Suhrkamp).

Hennig Leal, Mônia Clarissa (2014): “A dignidade humana como critério para o controle jurisdicional de políticas públicas: análise crítica da atuação do Supremo Tribunal Federal”, en Direitos sociais e políticas públicas: desafios contemporâneos (Santa Cruz do Sul, Edunisc), Tomo 13, pp. 196-226.

(2007): Jurisdição Constitucional Aberta. Reflexões sobre a Legitimidade e os Limites da Jurisdição Constitucional na Ordem Democrática (Rio de Janeiro, Lumen Juris).

Hennig Leal, Mônia Clarissa; Maas, Rosana Helena (2014): O Amicus Curiae e o Supremo Tribunal Federal: fundamentos teóricos e análise crítica (Curitiba, Multideia).

(2019): "Políticas públicas e o "fuzzysmo" da efetividade dos direitos fundamentais sociais: análise crítica do Are 639.337/STF - acesso à educação", en Interlocuções jurídicas Luso-Brasileiras: Interlocuções sobre Direito (Braga, Aedrel).

Hesse, Konrad (1994): Grundzüge des Verfassungsrechts der Bundesrepublick Deutschland. 20., neubearbeitete Auflage (Heidelberg, Müller Verlag).

(1996): "Significado de los derechos fundamentales", en Benda, E. et al. Manual de derecho constitucional (Madrid, Marcial Pons).

Holmes, Stephen; Sunstein, Cass. R. (2000): The cost of rights: Why Liberty Depends on Taxes (London, W. W. Norton \& Company). 
Kirste, Stephan (2013): “A dignidade humana e o conceito de pessoa do direito”, en: Wolfgang Sarlet, Ingo (org): Dimensões da dignidade: ensaios de filosofia do direito e direito constitucional (Traducc. Ingo Wolfgang Sarlet, Luís Marcos Sander, Pedro Scherer de Mello Aleixo, Rita Dostal Zanini; Porto Alegre, Livraria do Advogado Editora), pp. 175-198.

(2013): Introdução à filosofia do direito (Traducc. Paula Nasser, Belo Horizonte, Fórum).

(2018): Introdução à filosofia do direito (Traducc. Paula Nasser, Belo Horizonte, D’Plácido).

Klatt, Matthias (2015): "Direitos a prestações positivas: quem deve decidir? Controle judicial ponderado", en Alexy, R.; Baez, N. L. X.; Silva, R. L: Dignidade humana, direitos sociais e nãopositivismo inclusivo (Florianópolis), pp. 215-266.

Lazcano, A. J. M.; Cárdenas, J. C.; Torres, M. C. M (2017): “Análisis comparativo de los mecanismos de protección de derechos humanos en la omisión legislativa dentro del ordenamiento jurídico de México y Colombia”, en Estudios Constitucionales: Revista del Centro de Estudios Constitucionales (Año 15, № 2), pp. 229-272.

Leivas, Paulo Gilberto Cogo (2006): Teoria dos direitos fundamentais sociais (Porto Alegre, Livraria do Advogado Editora).

Mendes, Gilmar Ferreira (2012): Direitos Fundamentais e Controle de Constitucionalidade: Estudos de direito constitucional (São Paulo, Saraiva).

Michelman, Frank Isaac (2005): “A Constituição, os direitos sociais e a justificativa política liberal”, en Wolfgang Sarlet, Ingo (Org.): Jurisdição e Direitos Fundamentais (Porto Alegre, Livraria do Advogado Editora).

Miranda, Jorge (1986): "Os direitos fundamentais na ordem constitucional portuguesa", en Revista Española de Derecho Constitucional (№ 18), pp. 107-138.

Müller Bitencourt, Caroline (2013): Controle Jurisdicional de Políticas Públicas (Porto Alegre: Nuria Fabris). 
Nogueira Alcalá, Humberto (2012): “El bloque constitucional de derechos: La confluencia del derecho internacional y del derecho constitucional en el aseguramiento y garantía de los derechos fundamentales en América Latina”, en Llanos Mardones, Hugo Ignácio; Picand Albónico, Eduardo: Estudios de Derecho Internacional: libro homenaje al Profesor Hugo Llanos Mansilla (Santiago, Abeledo Perrot), pp. 265-304.

(2000): Teoría de los derechos fundamentales y los derechos humanos (Montevideo, Ingranusi).

Perez Luño, Antônio-Enrique (2013): "Aproximación al análisis conceptual de los derechos sociales", en Bravo, Á. S., et al: Derechos Sociales en tiempos de crisis (Sevilla, Punto Rojo Libros).

Piketty, Thomas (2014): O capital no século XXI (Rio de Janeiro, Intrínseca).

Petit Guerra, Luis Alberto (2017): “El diálogo entre doctrina, Constitución y Cortes para el establecimiento de los contenidos mínimos de derechos sociales fondamentales. La convergencia de categorías (con especial referencia al derecho al mínimo vital)”, en Revista Estudios Constitucionales (Año 15, № 2), pp. 203-228.

Queiroz, Cristina (2006): O princípio não reversibilidade dos direitos fundamentais sociais: princípios dogmáticos e prática jurisprudencial (Lisboa, Coimbra).

Saddy, André (2009): Discricionariedade Administrativa nas normas jurídicas em abstrato. Limites e Técnicas de Contenção (Rio de Janeiro, Lumen Juris).

Watanabe, Kazuo (2011): “Controle Jurisdicional das Políticas Públicas - 'Mínimo Existencial' e demais Direitos Fundamentais Imediatamente Judicializáveis”, en Pelegrini Grinover, Ada; Watanabe, Kazuo (Orgs.): O controle jurisdicional de políticas públicas (Rio de Janeiro, Forense).

Wolfgang Sarlet, Ingo (2004): A eficácia dos direitos fundamentais (Porto Alegre, Livraria do Advogado).

(2010): “Breves notas a respeito dos limites e possibilidades da aplicação das categorias de proibição de excesso e de insuficiência em matéria criminal: a necessária e permanente busca da superação dos fundamentalismos hermenêuticos”, em Gonçalves 
Fernandes, Bernardo: Interpretação Constitucional: reflexões sobre (a nova) hermenêutica (Salvador, Juspodivm).

Tribunal de Contas da União (2017): Aumentam os gastos públicos com judicialização da saúde, [Disponible en: https://bit.ly/32kPn1w]. [Fecha de consulta: 01 de abril de 2019].

Wunder Hachem, Daniel (2014): "Derechos fundamentales económicos y sociales y la responsabilidad del Estado por omisión”, en Estudios Constitucionales: Revista del Centro de Estudios Constitucionales, (№ 1), pp. 285-328.

Zagrebelsky, Gustavo (2014): La ley y su justicia (Madrid, Trotta).

\section{Jurisprudencia citada}

BRASIL. Supremo Tribunal Federal. Recurso Extraordinário № 657.718 Minas Gerais, Rel. Ministro Marco Aurélio, de 22 mayo 2019. [Disponible en: https://bit.ly/3eb6NDj]. [Fecha de consulta: 25 de noviembre de 2020]. 